\title{
Pharmacoepidemiological Study of Psychotropic Medication Use in Children with Developmental Disorders
}

\author{
Diana Gómez-Galicia ${ }^{1}$, Lourdes Rodríguez-Fragoso ${ }^{1}$, Miguel Sánchez-Alemán ${ }^{2}$, \\ Gabriela López-Aymes ${ }^{3}$, Valadez-Sierra Dolores ${ }^{4}$, Alfonso Castro ${ }^{5}$, And Jorge \\ Reyes-Esparza ${ }^{1}$. \\ ${ }^{1,}$ Universidad Autónoma del Estado de Morelos, Facultad de Farmacia \\ ${ }^{2,}$ Instituto Nacional de Salud Pública, Laboratorio de Infecciones de Transmisión Sexual \\ ${ }^{3,}$ Universidad Autónoma del Estado de Morelos, Facultad de Comunicación \\ ${ }^{4,}$ Universidad de Guadalajara, Departamento de Psicología Aplicada \\ ${ }^{5,}$ Universidad de Guadalajara, Departamento de Neurociencias
}

\begin{abstract}
Mental and behavioural disorders are common in childhood and adolescence, but less than one-fifth of these children receive the necessary treatments. Psychotropic medications are recommended for the treatment of a variety childhood and adolescent mental disorders, and the use of such medications has recently increased in many countries. The aim of the study was to investigate the use of prescription psychotropic medication among children with developmental disorders and predictors for said use. A cross-sectional paediatric study based on a questionnaire that was answered by the children's parents and corroborated by clinical records was used. Type and frequency of psychotropic use, reasons for use, and the determining factors were the main measure. In total, 64\% of children were receiving psychotropic medication; $40 \%$ of the drugs were prescribed in an off-label way, and $73 \%$ were meant to treat attention deficit hyperactivity disorder. The stimulant methylphenidate was the most commonly prescribed drug among both the diagnosed and undiagnosed children (89.6\% and 60\%, respectively), followed by the non-stimulant atomoxetine. Age (OR 3.7, 95\% CI 1.1 to 12.3), diagnosis (OR 8.1, 95\% CI 2.1 to 30.7) and the father being the head of the household (OR $5.8,95 \%$ CI 1.2 to 29.0) were determinants of psychotropic medication use. The most common psychotropic medication prescribed to children in developmental disorder care centres is the stimulant methylphenidate. These drugs are frequently prescribed in an off-label way to children despite a lack of evidence regarding medication efficacy and safety.
\end{abstract}

Keywords: Developmental disorders, children, psychotropic medication.

\section{INTRODUCTION}

Contrary to popular belief, mental and behavioural disorders are common in childhood and adolescence. Although the prevalence rates vary considerably between studies, it appears that $10 \%-20 \%$ of all children have one or more mental or behavioural disorders ${ }^{[1]}$. According to the Board of Health of the United States, one in 10 children have a mental illness severe enough to cause some degree of damage, but less than one-fifth of these children receive the necessary treatment ${ }^{[2]}$. Such treatment consists of a balanced combination of three components: medication (or pharmacotherapy), psychotherapy and social rehabilitation. The specifics will vary depending not only on the principal diagnosis but also on the existence of other mental and physical illnesses, age of the patient and stage when the disease is found ${ }^{[1,3,4]}$.

Psychotropic medications are recommended for the treatment of a variety of childhood and adolescent mental disorders $^{[3]}$, and their use has recently increased in many countries ${ }^{[5]}$. Only a few psychotropic medications have been approved for use among patients younger than 18 years old. The prevalence of treatment for children younger than 5 has not received much attention until recently. The approved and unapproved indications for psychotropic use in children are not extensive. The approved drugs include analgesics and sedatives/hypnotics for pain relief, hydroxyzine for situational anxiety, tricyclic antidepressants for nocturnal enuresis (6-year-olds and older), and amphetamines for $\mathrm{ADHD}^{[6]}$. Controlled trials have also evaluated antipsychotic medications for schizophrenia $^{[7]}$ and monotherapy using antipsychotics or mood stabilisers for bipolar disorder in younger patients ${ }^{[8,9]}$. The medication efficacy in these trials has not been robust, whereas the side-effect concerns and drop-out rates are considerable ${ }^{[10]}$. Given this context of chemically produced harm and benefit, paediatric psychoactive drug treatment raises particular anxieties given that children are seen as particularly vulnerable, physically and psychologically, to mood-altering substances. 
The use of psychotropic medication to treat children has become a highly contentious issue, receiving regular attention from academics, policymakers, and the lay press alike ${ }^{[11]}$. Little is known regarding the use of psychotropic medication among Mexican children. This study researched psychotropic use and predictors in relation to child and family characteristics that are collectively associated with current medication status.

\subsection{Design}

\section{MATERIALS AND METHODS}

A cross-sectional and descriptive study was conducted from June 2009 to June 2010 among children attending care centres for developmental disorders in Morelos and Jalisco (Mexico). The study protocol was approved by the institutional review board of the University of Morelos. Children who attended these care centres were eligible for inclusion. The primary aim of the study was to investigate the use of psychotropic medication among this population.

\subsection{Procedure}

The parents of the patients signed an informed consent form and answered a validated questionnaire. Individual records were assigned a random recipient identification number to maintain confidentiality. The data obtained included the age, gender, diagnosis, non-pharmacological treatment, number and types of psychotropic medications, and the adverse events associated with psychotropic medications. Parents were asked why each psychotropic medication was prescribed to identify a purpose. In addition, the parents were asked about adverse events related to the use of psychotropic medication. Clinical records were reviewed to corroborate the information about diagnosis, psychotropic medication, and attendant conditions provided by parents. The adverse events could not be corroborated in the clinical records because they did not contain that information. Therefore, adverse event reporting is solely based on what the parents reported regarding adverse events related to the use of psychotropic medication. Unmedicated children with complete information were taken as a reference group. Children with incomplete information were eliminated. The psychotropic medications were divided into stimulants and non-stimulants. In addition, they were identified by their generic name.

\subsection{Measures}

Psychotropic medication. Information about the use of any medication by children within the last months, secular changes, and indications were examined. Concomitant medication usage was examined. The secular changes were described by parents and included all changes from the beginning of the use of psychotropic medication. Off-label use was defined as use without license for indication and/or age. We also included patients who were still being evaluated, even if they did not have a formal diagnosis. No data on the use of medication and complete information were available for 36 children. These subjects were excluded from the analysis. To identify the determinants related to the use of psychotropic medication, we compared the medicated group with the unmedicated one.

\subsection{Analysis}

Differences in the proportion of children with or without psychotropic medication and those with and without an established diagnosis were assessed for statistical significance using the $X^{2}$ test, where $\mathrm{p}<0.05$ was considered to be statistically significant. A multivariate logistic regression model was used to identify child and family characteristics collectively associated with current use of medication. Regarding the factors associated with psychotropic use, a number of child and family characteristics were cross-tabulated with non-psychotropic medication treatment with confidence intervals of $95 \%\left(\mathrm{CI}_{95 \%}\right)$ and evaluated with the $X^{2}$ test.

\section{RESULTS}

\subsection{Demographic data}

A total of 126 questionnaires were applied in care centres for children with developmental disorders; 90 children were eligible for inclusion according to our criteria. The demographic and clinical data of the 90 eligible children are summarised in Table 1. Of the eligible population, 58 (64.4\%) were school-aged children (7-13 years), and $32(35.6 \%)$ preschoolers (4-6 years). In addition, 73 children $(81.1 \%)$ were male, and 17 $(18.9 \%)$ were female. According to our results, the main reason children attended these centres was attention deficit hyperactivity disorder (ADHD), which was diagnosed in 63 children. Two children were diagnosed with seizures. It should be noted that 25 children did not have a definite diagnosis because they were still under evaluation. Eighty-one children $(90 \%)$ were receiving non-pharmacological therapy, which included psychological, behavioural and learning therapy. In the case of 54 children $(60 \%)$, the father was the family breadwinner and had, at most, a middle-school education. In addition, $81.1 \%$ of the children using psychotropic medication lived in a family of 1 to 3 children. 
Pharmacoepidemiological Study...

Table 1 Demographic characteristics of the study population

\begin{tabular}{|c|c|c|c|c|}
\hline CHARACTERISTIC & $\begin{array}{c}\text { Total population } \\
(\mathrm{N}=90)\end{array}$ & $\begin{array}{c}\text { With psychotropic } \\
\text { medication } \\
(\mathrm{N}=58)\end{array}$ & $\begin{array}{l}\text { Without psychotropic } \\
\text { medication }(\mathrm{N}=32)\end{array}$ & p Value \\
\hline Age (years) & & n $(\%)$ & & \multirow[b]{2}{*}{$0.041 *$} \\
\hline $\begin{array}{l}4-6 \\
7-13\end{array}$ & $\begin{array}{l}32(35.6) \\
58(64.4)\end{array}$ & $\begin{array}{l}16(50.0) \\
42(72.4)\end{array}$ & $\begin{array}{l}16(50.0) \\
16(27.6)\end{array}$ & \\
\hline Sex & & & & \\
\hline Male & $73(81.1)$ & $48(65.8)$ & $25(34.2)$ & \multirow{2}{*}{0.587} \\
\hline Female & $17(18.9)$ & $10(58.8)$ & $7(41.2)$ & \\
\hline Diagnosis & & & & \multirow{4}{*}{$0.008 *$} \\
\hline ADHD & $63(70.0)$ & $46(73.0)$ & $17(27.0)$ & \\
\hline In evaluation & $25(27.8)$ & $10(40.0)$ & $15(60.0)$ & \\
\hline Seizures & $2(2.2)$ & $2(100.0)$ & 0 & \\
\hline Non-pharmacologic treatme & & & & \\
\hline Yes & $81(90.0)$ & $55(68.0)$ & $26(32.0)$ & \multirow{2}{*}{0.063} \\
\hline No & $9(10.0)$ & $3(33.0)$ & $6(66.0)$ & \\
\hline Head of Household & & & & \\
\hline Father & $54(60.0)$ & $40(74.0)$ & $14(26.0)$ & \multirow{3}{*}{$0.023 *$} \\
\hline Both & $22(24.4)$ & $13(59.0)$ & $9(41.0)$ & \\
\hline Mother, Other & $14(15.6)$ & $5(35.7)$ & $9(64.3)$ & \\
\hline Head of household education & & & & \\
\hline Elementary school & $24(26.7)$ & $20(83.0)$ & $4(17.0)$ & \multirow{3}{*}{$0.023 *$} \\
\hline High school & $48(53.3)$ & $28(58.0)$ & $20(42.0)$ & \\
\hline Degree & $18(20.0)$ & $10(56.0)$ & $8(44.0)$ & \\
\hline Children at home & & & & \\
\hline $1-3$ & $73(81.1)$ & $48(66.0)$ & $25(34.0)$ & \multirow{2}{*}{0.587} \\
\hline $4-6$ & $17(18.9)$ & $10(58.8)$ & $7(41.2)$ & \\
\hline Medical care & & & & \\
\hline Assistive care & $20(22.2)$ & $18(90.0)$ & $2(10.0)$ & \multirow{3}{*}{0.239} \\
\hline Social security & $40(44.4)$ & $24(60.0)$ & $16(40.0)$ & \\
\hline Private & $30(33.3)$ & $16(53.0)$ & $14(47.0)$ & \\
\hline
\end{tabular}

* statistically significant

In 40 cases (44.4\%), medical assistance was received through social health services, whereas 30 children (33.3\%) saw private practitioners. The 90 children were divided, depending on treatment, into groups of users and nonusers of psychotropic medications. We observed that 58 children (64.4\%) were using psychotropic medication, and $32(35.6 \%)$ did not. Of the children receiving psychotropic medication, $72.4 \%$ $(42 / 58)$ of the school-aged children received medication, and 50\% (16/32) of the preschoolers received medication $(\mathrm{p}=0.041)$. In addition, 65.8\% (48/73) of males and 58.8\% (10/17) of females used psychotropic medication $(\mathrm{p}=0.587)$. For 46 children $(73.0 \%)$, the reason for drug therapy was ADHD and, for two children, the reason was seizures. It should be noted that 10 children $(40 \%)$ who were still being evaluated were receiving psychotropic medication $(\mathrm{p}=0.008)$. Of the children receiving psychotropic medication, $68.0 \%$ were also receiving non-pharmacological treatment, and $33.0 \%$ were not $(\mathrm{p}=0.063)$. The percentage of children using psychotropic medicines whose fathers were the family breadwinner was $74.0 \%$, whereas for $59.0 \%$, the breadwinner was both the father and mother and for $35.7 \%$ of the children, the breadwinner was the mother or another relative ( $\mathrm{p}=0.023)$. Of the family breadwinners, $83 \%$ had elementary school-level education, $58 \%$ had high school educations and $56 \%$ had a college degree $(\mathrm{p}=0.023)$. In addition, $66 \%$ of children using psychotropic medication lived in families of 1 to 3 children, and 58.8\% lived in families with 4-6 children $(\mathrm{p}=0.587)$. There was no significant difference regarding the type of medical assistance in this group, though the majority received care via social health care institutions.

Unlike those receiving psychotropic medication, there was a greater percentage of preschool age children not receiving psychotropic medication (50\%) than school age children (27.6\%). A similar trend in sex was observed, as there were more females $(41.2 \%)$ than males $(34.2 \%)$ not receiving medication. Of the children not receiving medication, $27 \%$ were diagnosed with ADHD, and a great number were still under evaluation (60\%). Most of the children were receiving non-pharmacologic treatment (66\%). Another difference with those in the psychotropic medication group was the family breadwinner. In the non-medication group, the mother and other relative breadwinner percentage (64\%) was higher. The education of these mothers and other relatives was high compared with the education of family breadwinner of the psychotropic medication users.

Figure 1 shows the distribution frequency of psychotropic medication use by age, with a high frequency among preschoolers; 5-year-olds presented a higher rate of use (50\%) and 4-year-olds presented a lower rate of use $(18.7 \%)$. 
In the school-aged group, the highest frequency of medication use was among 7-10-year-olds, and there was a decrease among those who were 11 years and older.

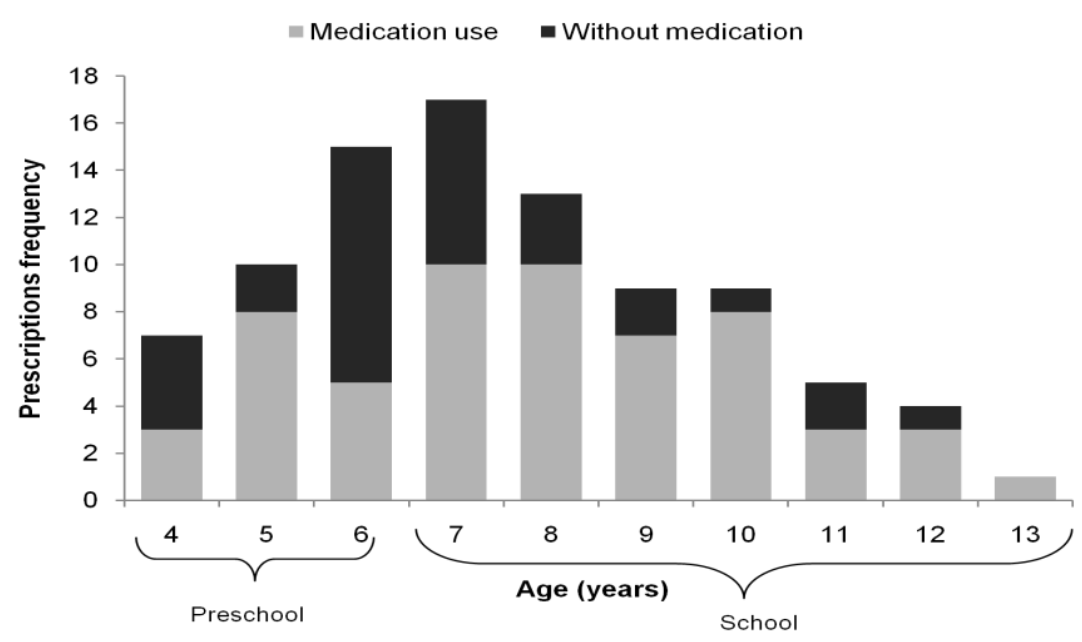

FIGURE 1. Age-frequency distribution of the use of psychotropic medication

\subsection{Psychotropic medications}

Nine different types of psychotropic medications were prescribed to the population (Table 2). Stimulants were the most common $(84.4 \%)$, specifically methylphenidate, whereas non-stimulant medications were used in $46.5 \%$ of the cases. The non-stimulant medications included atomoxetine and valproate, among others.

\begin{tabular}{|c|c|c|c|c|c|c|c|}
\hline & & \multirow{2}{*}{$\begin{array}{c}\text { Psychotropic } \\
\text { medication } \\
\text { received by child }\end{array}$} & \multicolumn{2}{|c|}{ Diagnosed } & & \multicolumn{2}{|c|}{ In evaluation } \\
\hline & & & Preschool & School & & Preschool & School \\
\hline & Drug & n $(\%)$ & & & $\mathbf{n}$ & & \\
\hline Stimulant & Methylphenidate & $49(84.4)$ & $13 / 43$ & $30 / 43$ & & --- & $6 / 6$ \\
\hline \multirow{8}{*}{$\begin{array}{l}\text { Non- } \\
\text { stimulant }\end{array}$} & Atomoxetine & $9(15.5)$ & $-\cdots$ & $8 / 8$ & & --- & $1 / 1$ \\
\hline & Risperidone & $6(10.3)$ & $1 / 5$ & $4 / 5$ & & --- & $1 / 1$ \\
\hline & $\begin{array}{l}\text { Magnesium } \\
\text { Valproate }\end{array}$ & $4(6.9)$ & $1 / 3$ & $2 / 3$ & & --- & $1 / 1$ \\
\hline & Carbamazepine & $2(3.4)$ & $1 / 2$ & $1 / 2$ & & $-\cdots$ & $-\cdots$ \\
\hline & Phenobarbital & $2(3.4)$ & $1 / 1$ & $-\ldots$ & & & \\
\hline & Fluoxetine & $1(1.7)$ & ---- & $1 / 1$ & & $-\cdots$ & $-\cdots$ \\
\hline & Phenytoin & $2(3.4)$ & $1 / 2$ & $1 / 2$ & & ---- & ---- \\
\hline & Piracetam & $1(1.7)$ & ---- & --- & & $-\cdots$ & $1 / 1$ \\
\hline
\end{tabular}

As mentioned, $79.3 \%$ of the children taking psychotropic medication had a confirmed ADHD diagnosis. In $93.5 \%$ of the cases, methylphenidate was the treatment of choice; atomoxetine was chosen in $6.5 \%$ of cases. Multimodal therapy was frequent; $95.7 \%$ of the children were receiving complementary therapy in addition to psychotropic medication; $4.3 \%$ of the children took only psychotropic medication. On the other hand, we must highlight the prescription of psychotropic medication to children still under evaluation. Methylphenidate was used most frequently among the school-aged children; however, we also detected the use of non-stimulant medication. It should be noted that there was no use of psychotropic medication in preschoolers.

The majority of the children treated with psychotropic medications received them as monotherapy (79.3\%). In addition, $20.7 \%$ of the medicated children received psychotropic medication as combined therapy with 2 or 3 other medications. Methylphenidate was the most widely used drug in both monotherapy and combination therapy. In the case of combination therapies, the most frequently used drug was methylphenidate with risperidone, and methylphenidate was the most frequently used with anticonvulsants. The main reason for the combination therapies was the presence of attendant conditions such as seizures and disruptive behaviours.

Because psychotropic medication is controlled and its use in children should be monitored, the medications in this study were used in a variety of ways (Table 3), including the following: 1) modifications in the active substance $(61.1 \%)$ by changing from a stimulant to a non-stimulant, e.g., methylphenidate to risperidone or methylphenidate to atomoxetine; 2) modifications in the medicine brand in $50 \%$ of the cases, most often from a 
generic to brand name and vice versa (6 and 3 changes, respectively); 3 ) changes in formulation, moving from immediate to extended-release presentations in 3 cases; and 4) 2 and 3 consecutive changes in the treatment of 3 cases that included branding, formulation and active substance. In all 3 cases, the initial psychotropic was the stimulant methylphenidate, and the final psychotropic was a non-stimulant. Among the diagnosed preschoolers, the when there were modifications they were mostly changes in the active substance. There were few modifications in the evaluation group, and these changes involved the active substance and entailed more consecutive changes.

Table 3 Changes in psychotropic medication

\begin{tabular}{lcccccc}
\hline & & & \multicolumn{2}{c}{ Diagnosed } & & \multicolumn{2}{c}{ In evaluation } \\
Changes n=18 $\mathbf{( 3 1 . 0 \% )}$ & Total changes & Preschool & School & & Preschool & School \\
\hline & & & & & & \\
Brand & 3 & $1 / 9$ & $8 / 9$ & & ---- & ---- \\
Formulation & 11 & ---- & $3 / 3$ & & ---- & ---- \\
Active substance & 3 & $3 / 10$ & $7 / 10$ & & ---- & $1 / 1$ \\
Two consecutive changes & 3 & --- & $1 / 1$ & & ---- & $2 / 2$ \\
Three or more & & --- & $3 / 3$ & & ---- & ---- \\
\hline Abbreviations: C, number of changes; $P$, total patients with changes & & &
\end{tabular}

\subsection{Predictors of psychotropic use}

Multiple logistic regression analysis revealed that school-aged children were more likely to receive medication than preschoolers $(\mathrm{OR}=3.7,95 \% \mathrm{CI}=1.1-12.3)$ (Table 4). However, there was a high prescription rate among preschoolers (43.8\%). Children who had a defined diagnosis were more likely to be prescribed drugs than those under evaluation $(\mathrm{OR}=8.1,95 \% \mathrm{CI}=2.1-30.7)$. Interestingly, however, $17.2 \%$ of children still under evaluation were receiving psychotropic medication.

Other factors included the role of the father as the family breadwinner. This factor made medication use almost six times more likely $(\mathrm{OR}=5.8,95 \% \mathrm{CI}=1.2-29)$. In the bivariate analysis, lower educational levels of the family breadwinner were associated with a greater likelihood that the child was receiving medication $(\mathrm{p}=0$. $05)$, but this relationship was not significant in a multivariate regression analysis $(p=0.434)$. Gender, nonpharmacological treatment and the type of medical assistance did not predict the prescription of psychotropic medication.

Table 4. Association between patient characteristics and medication use

\begin{tabular}{|c|c|c|c|c|c|}
\hline CHARACTERISTIC & Medicated \% & OR $\left(\mathbf{C I}_{95 \%}\right)$ & p Value & $\operatorname{ORa}\left(\mathbf{C I}_{95 \%}\right)$ & p Value \\
\hline \multicolumn{6}{|l|}{ Age (years) } \\
\hline $7-13$ & 71.4 & $3.3(1.3-8.3)$ & 0.012* & $3.7(1.1-12.3)$ & $0.033 *$ \\
\hline \multicolumn{6}{|l|}{ Sex } \\
\hline Male & 65.8 & $1.3(0.4-3.9)$ & 0.592 & $1.5(0.3-6.4)$ & 0.6 \\
\hline Yes & 73.0 & $4.1(1.5-10.7)$ & $0.005 *$ & $8.1(2.1-30.7)$ & \multirow[t]{2}{*}{$<0.001 *$} \\
\hline In evaluation & 40.0 & 1.0 & & 1.0 & \\
\hline \multicolumn{6}{|c|}{ Non-pharmacologic treatment } \\
\hline Yes & 67.9 & $4.2(1.0-18.3)$ & 0.053 & $5.0(0.6-42.6)$ & \multirow[t]{2}{*}{0.138} \\
\hline No & 33.3 & 1.0 & & & \\
\hline \multicolumn{6}{|c|}{ Head of household education } \\
\hline Elementary school & 83.3 & $4.0(0.97-16.5)$ & 0.056 & $2.1(0.3-13.6)$ & 0.434 \\
\hline High school & 58.3 & $1.1(0.4-3.3)$ & 0.839 & $0.5(0.1-2.1)$ & 0.346 \\
\hline Degree & 55.6 & 1.0 & & 1.0 & \\
\hline \multicolumn{6}{|l|}{ Medical care } \\
\hline Assistive care & 78.9 & $3.5(0.9-13.1)$ & 0.063 & $3.3 .1(0.6-16.8)$ & 0.147 \\
\hline Social security & 64.7 & $1.7(0.6-4.7)$ & 0.298 & $1.3(0.3-4.7)$ & 0.701 \\
\hline Particular & 51.7 & 1.0 & & 1.0 & \\
\hline
\end{tabular}

*statistically significant

\subsection{Adverse events}

We analysed the adverse events associated with the use of psychotropic medication in the diagnosed children and those still under evaluation (Table 5). The most frequently reported adverse events for stimulants were loss of appetite $(29.31 \%)$ and nervousness $(15.52 \%)$. In the case of non-stimulants, the most frequent 
adverse event was headache (6.90\%). There were more reports of adverse events in children receiving nonstimulant treatments than in those receiving stimulants. The less common adverse events for this group of medications, such as vomiting, hives, fever, nervousness, vertigo and aggressiveness, were only observed among patients still under evaluation.

The least frequent adverse events were only reported among children still under evaluation. These included vomiting, hives, and fever with the stimulant methylphenidate, and nervousness, dizziness and aggression with non-stimulants. Children diagnosed with ADHD reported, on average, one adverse event per child, whereas those under evaluation reported an average of 3.3 adverse events per child. The proportion of reported adverse events was 4:1 for stimulants vis-à-vis non-stimulants and 2:1 for preschoolers vis-à-vis school-aged children.

Table 5 Adverse Events

\begin{tabular}{|c|c|c|c|c|}
\hline \multirow{2}{*}{ Psychotropic medication } & \multirow{2}{*}{ Adverse Event } & Total & \multirow{2}{*}{$\frac{\text { Diagnosed }}{(n) \%}$} & \multirow[t]{2}{*}{ In evaluation } \\
\hline & & & & \\
\hline \multirow[t]{16}{*}{ Stimulant } & Loss of appetite & (17) 29.31 & (16) 33.3 & (1) 10 \\
\hline & Nervousness & (9) 15.52 & (7) 14.6 & (2) 20 \\
\hline & Insomnia & (7) 12.07 & (6) 12.5 & (1) 10 \\
\hline & Hyperactivity & (6) 10.34 & (6) 12.5 & \\
\hline & Headache & (6) 10.34 & (5) 10.4 & (1) 10 \\
\hline & Nausea & (4) 6.90 & (3) 6.3 & (1) 10 \\
\hline & Sleepiness & (3) 5.17 & (2) 4.2 & (1) 10 \\
\hline & Vertigo & (2) 3.45 & (1) 2.1 & (1) 10 \\
\hline & Tachycardia & (3) 5.17 & (3) 6.3 & ---- \\
\hline & Tics & (3) 5.17 & (3) 6.3 & ----- \\
\hline & Abdominal pain & (2) 3.45 & (1) 2.1 & (1) 10 \\
\hline & Vomiting & (1) 1.72 & -- & (1) 10 \\
\hline & Aggressiveness & (1) 1.72 & (1) 2.1 & --- \\
\hline & Dyskinesia & (1) 1.72 & (1) 2.1 & ---- \\
\hline & Urticaria & (1) 1.72 & --- & (1) 10 \\
\hline & Fever & (1) 1.72 & ----- & (1) 10 \\
\hline \multirow[t]{17}{*}{ Non-stimulant } & Headache & (4) 6.90 & (3) 6.3 & (1) 10 \\
\hline & Loss of appetite & (2) 3.45 & (1) 2.1 & (1) 10 \\
\hline & Abdominal pain & (4) 6.90 & (3) 6.3 & (1) 10 \\
\hline & Sleepiness & (4) 6.90 & (2) 4.2 & (2) 20 \\
\hline & Hyperactivity & (3) 5.17 & (3) 6.3 & ---- \\
\hline & Blurred vision & (2) 3.45 & (1) 2.1 & (1) 10 \\
\hline & Vomiting & (2) 3.45 & (2) 4.2 & ---- \\
\hline & Nauseas & (2) 3.45 & (2) 4.2 & ----- \\
\hline & Urticaria & (1) 1.72 & (1) 2.1 & ----- \\
\hline & Palpitations & (1) 1.72 & (1) 2.1 & ----- \\
\hline & Seizures & (1) 1.72 & (1) 2.1 & ----- \\
\hline & Cramps & (1) 1.72 & (1) 2.1 & ----- \\
\hline & Insomnia & (2) 3.45 & (1) 2.1 & (1) 10 \\
\hline & Urge to eat & (2) 3.45 & (1) 2.1 & (1) 10 \\
\hline & Nervousness & (1) 1.72 & ---- & (1) 10 \\
\hline & Vertigo & (1) 1.72 & ----- & (1) 10 \\
\hline & Aggressiveness & (1) 1.72 & ----- & (1) 10 \\
\hline
\end{tabular}

\section{DISCUSSION}

The incidence of disorders in children is poorly understood because of the lack of standardised instruments that have prognostic significance ${ }^{[12]}$. This complicates the task of assessing, diagnosing and treating this population that, because of its lower overall development and maturity, specifically language, is in many cases difficult, and therefore can lead to misdiagnosis and consequently an unnecessary or inappropriate treatment. Psychotropics are widely used to treat mental health disorders among the paediatric population ${ }^{[1]}$. Despite the important advances in paediatric clinical pharmacology regarding the safety and efficacy of psychotropic medication, reliable information on the pharmacoepidemiology of these medications in the Mexican population is scarce. There are, however, substantial intra- and inter-local variations in drug use profiles; this is due to a wide difference in market drug availability and official stances regarding their use across countries. Currently, there is no information regarding psychotropic prescriptions to Mexican children. For this reason, the present cross-sectional study was designed to highlight the clinical use of psychotropic medication in a group of Mexican children attending child developmental disorder care centres. 
Our study observed that $58(64.4 \%)$ of children were receiving psychotropic medication. This high rate agreed with previous reports regarding an overall increase in psychotropic-based treatment of children ${ }^{[5,13-15]}$. The present study found that the most school-aged children $(72.4 \%)$ were prescribed psychotropic medication, as expected; the use of medication was most prevalent among children 7 to 11 years old. However, the preschool group (those under 6 years old) displayed a high frequency of psychotropic medication use (50\%), mainly among 5 years old. These data differ from other studies on children where a higher frequency of use was observed in diagnosed 10- to 18 -year-old children ${ }^{[16-19]}$. These differences are most likely due to the early use of pharmacological treatment in our population as a result of long and complex involving establishing a diagnostic in this age group, and for these type of disorders, entering treatment prior to establishing the diagnosis. Although different methods and study populations were examined, our results agree with the results of other studies in different countries that report on a substantial use of psychotropic medication among school-aged and preschool children population ${ }^{[5,6,17,20-23]}$. We observed that the use of psychotropic medication among Mexican preschoolers was more frequent than in other countries. Approximately $50 \%$ of preschool children in our study population received psychotropic medication, whereas other studies have reported a maximum of $17 \%$ or less of preschoolers using psychotropic medication ${ }^{[19,24,25]}$ in outpatient settings.

The use of psychotropic medication has been reported frequently in school-age children, however, in our study, we observed that a great use of psychotropic medication use occurred with children under 6 years. Some authors have reported the existence of a significant association between age and diagnosis of children with disorders of childhood and adolescence. The most common disorders in children of $0-5$ years are behavioural disorders, communication, pervasive developmental disorders, and the removal and control of impulses $^{[26]}$, disorders that do not necessarily require a drug but instead a non-pharmacological treatment. Children aged 6-11 have more behavioural problems, often followed by ADHD, which are usually treated with psychotropic medication and other therapies. The most prevalent diagnosis among children receiving psychotropic medication was ADHD (73\%). Lares Assef and cols; reported the use of psychotropic medication in Mexican children with ADHD in a hospital setting as the primary reason for the medication $(23.4 \%)^{[27]}$. Although the scenario is different, the use of psychotropic medication in children with ADHD is similar. Whereas, in other countries, the use of psychotropic medications is indicated for depression, sleep disorders and obsessive-compulsive disorder. On the other hand, Zito and cols ${ }^{[19]}$; reported the use of psychotropic medication with the main reasons of ADHD (38.8\%), depression (35.5\%) and adjustment/anxiety (33.7\%) among U.S. children on Medicaid insurance.

ADHD is the most common mental disorder in children in many countries ${ }^{[28]}$. ADHD is a behavioural disorder of childhood and adolescence. Primary care physicians and paediatricians are increasing the diagnosis and management of ADHD with psychotropic medication, as these drugs are the first line of treatment for this $\operatorname{disorder}^{[29]}$. However, psychotropic medication is also extensively used for other mental disorders such as depression, anxiety disorder, and oppositional defiant disorder that are also common in children. Our population did not report these disorders, but other disorders related to age, such as generalised developmental disorders of language, learning and behavioural problems, were found. Perhaps this difference is related to the setting of the present study which, in this case, did not involve hospitals, medical surveys or databases.

In our population, an important number of children still under evaluation were receiving psychotropic medication (40\%) and, therefore, there were no valid reasons for prescribing these children psychotropics. Offlabel prescription to children is unfortunately very common in the United States and Europe, with a rate of over $60 \%{ }^{[30,31]}$. A large proportion of children are medicated without precaution, and this may be an increased risk factor for other types of disorders such as loss of appetite, insomnia and increased heart rate that may endanger the child's life. The successful treatment of mental disorders at a young age has the potential to reduce adult morbidity. However, successful treatment demands a diagnosis and medication use, as well as precise indications. In addition, official indications for the most commonly used psychotropic medications in children are not officially established, and off-label prescriptions have quickly expanded across the world during the past decade $^{[32-34]}$. This expansion could be related to the fact that in many cases the prescription does not come from a specialist but rather from a general physician and is based on a lack of relevant assessment and monitoring. There are safety issues related to psychotropic off-label use. The presence of adverse events was more common and severe in undiagnosed children than in diagnosed ones $(4: 1)$. It has been reported that about one-third of the side effects in children are due to psychotropic drugs ${ }^{[35]}$ and are age-related. In many cases, the lack of a diagnosis is most likely due to the severity of the behavioural problems, which create an immediate need to control and reduce the associated social and school-related problems. It is certainly easier to use medications when attempting to control and decrease these problems. Hyperactivity and hallucinations/delusions are the main problems for teachers and can lead to the use of pharmaceutical treatment ${ }^{[29]}$. 
The current study indicates that psychotropic stimulants were used by $84.4 \%$ of children, whereas nonstimulants were only prescribed to $46.5 \%$. Stimulants were the most common across both age groups, preschoolers and school-aged children (68\% and 67\%, respectively). More than half of the study population received stimulant treatment. This can be compared to other countries such as the United States and France, where the overall psychotropic use is $70.7 \%$ and $46 \%$, respectively, and antipsychotics are the most frequently used psychotropic medication class $(44 \%)^{[16,24,32]}$. Others studies have reported that the most frequently used paediatric psychotropics are antidepressants, selective serotonin reuptake inhibitors (SSRIs) such as fluoxetine and sertraline, and stimulants ${ }^{[13,24,36,37]}$. This is most likely due to differences in diagnosis.

The stimulant methylphenidate was the most commonly used psychotropic among diagnosed children and children under evaluation, followed by the non-stimulants atomoxetine and risperidone at $12.1 \%$ and $10.3 \%$, respectively. It must be noted that treatment among children under diagnostic evaluation was slightly different: valproate and risperidone were the most commonly prescribed non-stimulants, which suggests the medications were used to treat specific symptoms such as anxiety, inattention, hyperactivity, or irritability but not a specific condition. Optimal child treatment should include a diagnosis followed by medication because the purpose of the treatment is not only to calm the child but to provide integral and appropriate care to avoid future complications. It would appear that, at least in our population, that rather than treating a medical disorder, methylphenidate is being used to manage adult-child conflict in contexts where the child is expected to possess self-control and the ability to focus from a young age.

Stimulants are not approved for children under 6 years of age due to lack of efficacy and safety in that age group. We observed that methylphenidate was widely used across all age groups, most frequently for children younger than 10, whereas, as mentioned by Zito in a population-based analysis of populations in the U.S. health care system, children aged 10 to 14 years were the predominant stimulant-treated age group. That stimulants should comprise the majority of psychotropic medications prescribed to ADHD diagnosed children is not surprising and is consistent with a number of previous studies ${ }^{[37,38]}$. What is less clear is how often stimulants are used with other psychotropic medications and which regimens are the most prevalent. Our study found that stimulants were used both as monotherapy (79.2\%) and alongside non-stimulants (20\%). The most prevalent combinations were stimulants with antipsychotics (e.g., risperidone) and mood stabilisers (e.g., valproate and carbamazepine). These findings differ from those reported by Guevara et al using data from the Group Health Cooperative of Puget Sound $(\mathrm{GCH}){ }^{[37]}$, a large non-profit organisation in western Washington state (United States). They reported that the most prevalent multiple regimens were stimulants with $\alpha$ adrenergic agonists, SSRIs, or TCAs.

The risperidone and methylphenidate combination has been recommended when ADHD patients remain problematic or are so extreme that they pose a danger to themselves or others. However, scientific databases available to clinicians regarding medications efficacy or safety remain limited because they may exacerbate some symptoms ${ }^{[39,40]}$. There is little evidence regarding the efficacy and safety of combining stimulants with mood stabilisers; the efficacy of stimulants decreases in these combinations in comparison with other non-stimulants, such as atomoxetine, because there is a risk of developing seizures ${ }^{[41]}$.

Stimulants and antidepressants show the most adverse events. There are huge evidence gaps regarding child medication safety as only a few child-prescribed medicines are clinically tested and licensed for paediatric use. Reports involving psychotropic safety among children have been conducted on patients between 6 and 12 years of age, but, in many cases, these drugs are not officially approved for children under $6{ }^{[33]}$ given the lack of drug efficacy and safety ${ }^{[42]}$. Many of these studies have outlined a number of concerns regarding pharmacotherapy in very young children, mostly across 3 major areas: 1) the short- and long-term safety of these agents in very young children, particularly possible effects on the developing brain; 2) the lack of efficacious data demonstrating that these medications attenuate the targeted behavioural and emotional symptoms; and 3) the context in which these medications are prescribed ${ }^{[25]}$. Regulatory authorities recommend special care because the minds and bodies of children are undergoing rapid development and are, therefore and in theory, more prone to "major and serious disruptions." Children may also be more physically susceptible to drug action and discomforted by even minor side effects; there is also an increased possibility of abuse or dependence than with adolescents or adults, mainly in the case of off-label prescription. Additionally, children's dependent status and inability to take treatment-related decisions introduces complex ethical dilemmas regarding informed consent. A large number of school-aged children were diagnosed with ADHD diagnosis and medicated when the father was the family breadwinner. This suggests that, rather than a high economic income, the acceptance of medication is related to the presence of the mother at home and daily school and home problems. Presumably, professional help is sought and medication is immediately accepted. Our results differ 
from others who reported recorded parental reluctance to seek out pharmacological treatment as an option, associating it with identification mechanisms. Parents thought treatment with psychotropics (mainly methylphenidate) would alienate their children from their peers and lead to difference and isolation ${ }^{[29]}$. It can be said that psychotropic use among the studied population is largely justified, but a number of children (40\%) were using psychotropic medications for no reason or off-label, as well as during their preschool years. There are potential psychotropic-related risks for this group given insufficient information on use, efficacy and adverse effects, and the drugs are not recommended for this age group. The study found that children who receive medication without a diagnosis had more adverse effects than those who had been diagnosed. Adverse effects are also higher among the preschool group, which suggests the severity of these effects should be evaluated and drugs should not be administered until such a study has been performed. Extensive psychotropic medication prescription among children and adolescents demands extensive prospective post-market studies to evaluate efficacy and safety.

The transversal nature of this study prevented us from monitoring the natural course of treatment, and this is a major limitation. Another limitation is that the information was provided by relatives and therapists but not hospitals or doctors. The diagnoses are based on medical reports from psychologists or therapists, regardless of their reliability or validity. Another limiting factor is the chosen study population (children attending developmental schools or centres). There are children who, for socioeconomic reasons, do not have access to such institutions.

\section{CONCLUSION}

In summary, psychotropics are frequently used among children attending care centres for child developmental disorders. The most commonly used drug is the stimulant methylphenidate. Psychotropic medications are frequently used among preschool children, a group currently lacking evidence of drug efficacy and safety and where it is difficult to establish a real diagnosis.

\section{ACKNOWLEDGEMENTS}

The authors would like to acknowledge the vital assistance of the researchers and staff at the Clínica de Comunicación Humana at the Universidad Autónoma del Estado de Morelos and CEADI, Morelos. The authors would also like to thank UAN, CEER, LAPSIEE, CAPSIEE in Jalisco, the CONACYT fellowship [Diana Gómez-Galicia] 205219, and the parents and children who participated in this study.

\section{REFERENCES}

[1] Serrano A, Palao D, Luciano J, Pinto A, et al. Prevalence of mental disorders in primary care: results from the diagnosis and treatment of mental disorders in primary care study (DASMAP). Soc Psychiatr Epidemiol,45,2010, 201-210.

[2] OMS and World Organization of Family Doctors (Wonca). Integrating mental health into primary care. A global perspective. Ginebra, Suiza: 2008.

[3] AACAP Work Group on Quality Issues. Practice parameter on the use of psychotropic medication in children and adolescents. J Am Acad Child Adolesc Psychiatry, Sep;48, 2009, 961-73.

[4] Comer S, Olfson M, Mojtabai R. National trends in child and adolescent psychotropic polypharmacy in office-based practice, 1996-2007. J Am Acad Child Adolesc Psychiatry 49(10), 2010, 1001-10.

[5] Olfson M, Marcus SC, Weissman MM, et al. National trends in the use of psychotropic medications by children. J Am Acad Child Adolesc Psychiatry,41, 2002;514-21.

[6] Zito JM, Safer DJ, dosReis. Trends in the prescribing of psychotropic medications to preschoolers. JAMA, 283, 2000,1025-30.

[7] Sikich L, Frazier JA, McClellan J, et al. Double-blind comparison of first-and second-generation antipsychotics in early-onset schizophrenia and schizoaffective disorder: Findings from the treatment of early-onset schizophrenia spectrum disorders (TEOSS) study. Am J Psychiatry, 165 2008,1420-31.

[8] Findling RL, McNamara NK, Branicky LA, et al. A double-blind pilot study of risperidone in the treatment of conduct disorder. J Am Acad Child Adolesc Psychiatry, 39, 2000,509-16.

[9] Wagner KD, Redden L, Kowatch RA, et al. A double-blind, randomized, placebo-controlled trial of divalproex extended-release in the treatment of bipolar disorder in children and adolescents. J Am Acad Child Adolesc Psychiatry,48, 2009,519-32.

[10] Correll CU, Manu P, Olshanskiy V. Cardiometabolic risk of second-generation antipsychotic medications during first-time use in children and adolescents. JAMA,302, 2009, 1765-73.

[11] Andrés Martin, Douglas Leslie. Trends in psychotropic medication costs for children and adolescents,1997-2000. Arch Pediatr Adolesc Med, 157, 2003,997-1004.

[12] Pedreira, J.L., La evaluación de los trastornos mentales en atención primaria. $49^{\circ}$ Congreso de la Asociación Española de Pediatría, Tenerife, España. 2000.

[13] Olfson M, Gameroff MJ, Marcus SC, et al. National trends in the treatment of attention deficit hyperactivity disorder. Am J Psychiatry 160, 2003,1071-1077.

[14] Moreno C, Laje G, Blanco C, et al. National trends in the outpatient diagnosis and treatment of bipolar disorder in youth. Arch Gen Psychiatry,64, 2007,1032-9.

[15] Olfson M, Blanco C, Liu L, et al. National trends in the outpatient treatment of children and adolescents with antipsychotic drugs. Arch Gen Psychiatry,63, 2006,679-85.

[16] Acquaviva E, Legleye S., Auleley Guy R., et al. Psychotropic medication in the French child and adolescent population: prevalence estimation from health insurance data and national self-report survey data. BMC Psychiatry, 2009;9(72).

[17] Zito JM, Safer DJ, dosReis, et al. Psychotropic practice patterns for youth: a 10 year perspective. Arch Pediatr Adolesc Med, 157, 2003,17-25. 
[18] Leslie Laurel K., Ramesh Raghavan, Jinjin Zhang, et al. Rates of psychotropic medication use over time among youth in child welfare/child protective services. J Child Adolesc Psychopharmaco,20(2), 2010,135-43.

[19] Zito JM, Safer DJ, Sai Devadatta, et al. Psychotropic medication patterns among youth in foster care. Pediatrics, 121(1), 2008,e157-e163.

[20] Zito JM, Safer DJ, dosReis, et al. Psychotherapeutic medication patterns for youths with attention-deficit/hyperactivity disorder. Arch Pediatr Adolesc Med, 153, 1999,1257-63.

[21] Rushton JL, Whitmire JT. Pediatric stimulant and selective serotonin reuptake inhibitor prescription trends: 1992 to 1998. Arch Pediatr Adolesc Med,155, 2001,560-5.

[22] Shatin D, Drinkard CR. Ambulatory use of psychotropics by employer-insured children and adolescents in a national managed care organization. Ambulatory Pediatrics,2, 2002,111-9.

[23] DeBar LL, Lynch F, Powell J, et al. Use of psychotropic agents in preschool children: associated symptoms, diagnoses, and health care services in a health maintenance organization. Arch Pediatr Adolesc Med,157, 2003,150-7.

[24] Comer S, Olfson M, Mojtabai R. National trends in child and adolescent psychotropic polypharmacy in office-based practice, 1996-2007. J Am Acad Child Adolesc Psychiatry,49(10), 2010,1001-10.

[25] Lynn L.DeBar, Frances Lynch, James Powell, et al. Use of psychotropic agents in preschool children. Arch Pediatr Adolesc Med,157, 2003,150-7.

[26] Navarro-Pardo Esperanza; Meléndez Moral Juan C; Sales Galán Alicia; Sancerni Beitia Ma Dolores. Desarrollo infantil y adolescente: trastornos mentales más frecuentes en función de la edad y el género.Psicotema,24(3),2012,377-383.

[27] Lares Assef Ismael, Sosa Macías M, Alanis Bañuelos R, et al. Farmacoepidemiología de psicofármacos empleados en la práctica en el servicio de psiquiatría infantil del hospital general de Durango, México. Bol Med Hosp Infant Mex, 67(1) 2010,27-36.

[28] Williams J, Klinepeter K, Palmes G, et al. Diagnosis and treatment of behavioural health disorders in pediatric practice. Pediatrics, 114, 2004,601-6.

[29] Lazaratou Helen, Anagnostopoulos Dimitris C., Alevizos Elias V., et al. Parental attitudes and opinions on the use of psychotropic medication in mental disorders of childhood. Annals of General Psychiatry, 6, 2007,32.

[30] Winterfeld U, Le Heuzey MF, Acquaviva E, et al. Off-label use of psychotropic medications in paediatric wards: A prospective study. Archives de Pédiatrie, 16, 2009,1252-60.

[31] Bazzano A, Mangione-Smith R, Schonlau M, et al. Off label prescribing to children in the United States outpatient setting. Academic Pediatrics, 9, 2009,81-8.

[32] Winterfeld U, Le Heuzey MF, Acquaviva E, et al. Psychotropic medication use in the child and adolescent psychiatry wards of French hospital. Pharm World Sci,30, 2008,600-4.

[33] Lakhan SE, Hagger-Johnson GE. The impact of prescribed psychotropics on youth. Clin Pract Epidemol Ment Health,3, 2007,21-3.

[34] Staller JA, Wade MJ, Baker M. Current prescribing patterns in outpatient child and adolescent psychiatric in central New York. J Child Adolesc Psychopharmaco,15, 2005,57-61.

[35] Aagaard Lise, Holme Hansen Ebba. The occurrence of adverse drug reactions reported for attention deficit hyperactivity disorder (ADHD) medications in the pediatric population: a qualitative review of empirical studies. Neuropsychiatr Dis Treat,7, 2011,729-44.

[36] Lares Assef Ismael, Sosa Macías M, Alanis Bañuelos R, et al. Farmacoepidemiología de psicofármacos empleados en la práctica en el servicio de psiquiatría infantil del hospital general de Durango, México. Bol Med Hosp Infant Mex 2010;67(1):27-36.

[37] Guevara James, Lozano Paula, Wickizer Thomas, Mell Loren and Gephart Harlan. Psychotropic medication use in a population of children who have attention-deficit/hyperactivity disorder. Pediatrics,109(5), 2002,733-9.

[38] Rappley M, Eneli I, Mullan P, Alvarez F, et al. Patterns of psychotropic medication use in very young children with attentiondeficit hiperactivity disorder. J Dev Behav Pediatr, 23(1) 2002,23-30.

[39] Pliszka SR, Crismon ML, Hughes CW, et al. The Texas children's medication algorithm project: revision of the algorithm for pharmacotherapy of attention-deficit/hyperactivity disorder. J Am Acad Child Adolesc Psychiatry,45, 2006,642-57.

[40] Nobuyasu B, Kayoko K, Hideo M. Predictive familial risk factors and pharmacological response in ADHD with comorbid disruptive behavior disorders. Pediatrics International,52, 2010,415-9.

[41] Niederhofer H. Combining carbamazepine, neuroleptics and acetylcholinesterase inhibitors with methylphenidate only reduces adverse side effects, but is less effective than a combination with atomoxetine. Med Hypotheses, 76(5), 2011,764-5.

[42] Aagaard Lise, Holme Hansen Ebba. The occurrence of adverse drug reactions reported for attention deficit hyperactivity disorder (ADHD) medications in the pediatric population: a qualitative review of empirical studies. Neuropsychiatr Dis Treat,7, 2011,729-44. 